\title{
Cortisol Stress Response in Men and Women Modulated Differentially by the Mu-Opioid Receptor Gene Polymorphism OPRMI AII8G
}

\author{
William R Lovallo*,1,2, Mary-Anne Enoch³, Ashley Acheson 4,5, Andrew J Cohoon', Kristen H Sorocco',6, \\ Colin A Hodgkinson ${ }^{3}$, Andrea S Vincent ${ }^{7}$, David C Glahn ${ }^{8,9}$ and David Goldman ${ }^{3}$
}

'VA Medical Center, Oklahoma City, OK, USA; '2Department of Psychiatry and Behavioral Sciences, University of Oklahoma Health Sciences Center, Oklahoma City, OK, USA; ${ }^{3}$ Laboratory of Neurogenetics, NIH, NIAAA, Bethesda, MD, USA; ${ }^{4}$ Department of Psychiatry, University of Texas Health Sciences Center at San Antonio, San Antonio, TX, USA; ${ }^{5}$ Research Imaging Institute, UTHSCSA, San Antonio, TX, USA; ${ }^{6}$ Donald W. Reynolds Department of Geriatric Medicine, OUHSC, Oklahoma City, OK, USA; ${ }^{7}$ Cognitive Science Research Center, University of Oklahoma, Norman, OK, USA; ${ }^{8}$ Olin Neuropsychiatry Research Center, Institute of Living, Hartford Hospital, Hartford, CT, USA; ${ }^{9}$ Department of Psychiatry, Yale University School of Medicine, New Haven, CT, USA

\begin{abstract}
Differences in stress reactivity may affect long-term health outcomes, but there is little information on how these differences arise. The stress axis is regulated by, in part, the endogenous opioid, beta-endorphin, acting on mu-opioid receptors. Persons carrying one or two copies of the G allele of the mu-opioid receptor gene (OPRM / A I 8G) may have higher receptor binding for beta-endorphin compared with AA homozygotes that may contribute to individual differences in cortisol reactivity to stress, leading to a relative blunting of cortisol stress reactivity in $\mathrm{G}$ allele genotypes. We measured cortisol in 25I young adults (69 GA/GG vs I82 AA genotypes) exposed to mental arithmetic plus public speaking stress relative to a resting control day. Women had smaller cortisol responses than men $(F=10.2$, $p=0.002)$, and women with $G A$ or $G G$ genotypes $(N=39)$ had an absence of cortisol response relative to $A A$ carriers $(N=1 / 0)$ $(F=18.4, p<0.0001)$. Male genotypes had no such difference in response $(F=0.29)$. Cortisol response following mu-opioid receptor blockade using naltrexone in 119 of these subjects unmasked a greater tonic opioid inhibition of cortisol secretion in women ( $N=64)$, consistent with their blunted stress reactivity. Compared with men, women may have cortisol stress responses that are more heavily regulated by endogenous opioid mechanisms, and the OPRMI GA/GG genotypes may affect females differentially relative to males. Diminished cortisol responses to stress may have consequences for health behaviors in women with GA/GG genotypes.

Neuropsychopharmacology (20I5) 40, 2546-2554; doi:I0.I038/npp.20I5.I0I; published online 6 May 2015
\end{abstract}

\section{INTRODUCTION}

Individual differences in stress reactivity contribute to the impact of stress on health (McEwen, 1998), and women and men are differentially vulnerable to the health effects of stress. Cortisol increases are a core component of the response to psychological stress, and cortisol in turn serves to regulate the systemic components of the stress response, therefore contributing to long-term homeostasis (De Kloet and Reul, 1987). Cortisol regulation of stress includes negative feedback at the hypothalamus (Dallman et al, 1987) and extrahypothalamic regions of the central nervous system (CNS), including the amygdala, hippocampus, and prefrontal cortex (Lovallo et al, 2010b; McEwen et al, 1968; Sanchez et al, 2000). Cortisol CNS feedback that departs from normal may therefore have implications for long-term

*Correspondence: Dr WR Lovallo, 755 Research Parkway, Suite 586, Oklahoma City, OK 73I04, USA, Tel: + 405456 3124, Fax: + I 405 456 1839, E-mail: bill@mindbodyl.org

Received 17 December 2014; revised 13 March 2015; accepted 15 March 2015; accepted article preview online 16 April 2015 regulation of emotions, behavior, and health (Sapolsky et al, 1985).

Cortisol secretion and its feedback effects are intimately tied to the endogenous opioid system: (a) Production of adrenocorticotropin in the pituitary mirrors that of the endogenous opioid agonist beta-endorphin (Nakao et al, 1978). (b) The endogenous opioid system in turn regulates the stress axis (Bilkei-Gorzo et al, 2008); opioid agonists buffer the cortisol response to stress (Drolet et al, 2001) while opioid antagonists precipitate a stress-like response by the hypothalamic-pituitary-adrenocortical (HPA) axis (Kreek, 2001; Lovallo et al, 2012; Mendelson et al, 1986). This suggests that variation in the mu-opioid system may modulate opioid effects on cortisol reactivity to stress.

We examined the impact of a functional single-nucleotide polymorphism (SNP) (A118G) in the gene encoding the opioid receptor, mu-1 (OPRM1) on variations in cortisol response to mental stress and naltrexone in men and women. The OPRM1 gene includes a coding SNP (A118G; Asn40Asp, rs1799971) that is common in Caucasians (HapMap frequency $=0.155$ ). One study showed that expression of the G118 variant in vitro resulted in a threefold increase in 
mu-opioid receptor binding relative to the more common A118 allele (Bond et al, 1998), although studies using human receptors have not observed this difference (Beyer et al, 2004; Kroslak et al, 2007; Zhang et al, 2005). This led us to expect that heterozygous and homozygous human carriers of the $\mathrm{G}$ allele (GA/GG) would show greater endogenous opioid restraint of the stress axis compared with AA homozygotes, resulting in blunted cortisol responses to psychological stress and larger responses to opioid antagonism, as shown by Wand and colleagues (Chong et al, 2006; Wand et al, 2002).

It is not known whether the OPRM1 A118G G allele affects cortisol reactivity differently in women than in men, although related evidence suggests this may be the case: (a) Women have much larger cortisol responses than men to the opioid receptor blocker, naltrexone (Lovallo et al, 2012), implicating greater tonic opioid restraint of the stress axis in women. (b) Men have larger cortisol responses to psychological stress than women, consistent with tonic opioid restraint of the HPA in women (Kudielka et al, 1998; Lovallo et al, 2010a). (c) A related OPRM1 polymorphism in primates $(\mathrm{C} 77 \mathrm{G})$ is associated with lower cortisol levels in females (Schwandt et al, 2011). (d) Female mice exposed to the mu-opioid receptor antagonist, naloxonazine, have a larger suppression of dopamine release in the nucleus accumbens compared with males (Job et al, 2007). Accordingly, we hypothesized that, if opioid regulation of the cortisol response is greater in women than in men, women should also show greater variation of cortisol secretion in relation to the OPRM1 A118G polymorphism than men. Specifically, we anticipated that GA/GG carriers would have smaller cortisol responses to mental stress than AA homozygotes, with a larger effect in women than in men.

We next examined the opioid nature of these genotype effects by measuring cortisol response to the mu-opioid antagonist naltrexone. Naltrexone's antagonism of the muopioid receptor makes it a useful pharmacological probe of the degree of opioid regulation over the HPA axis (Mendelson et al, 1986), and our previously observed sex difference in cortisol response to naltrexone makes it a useful means of examining differential opioid regulation in men and women who are AA $v s$ GA/GG carriers (Lovallo et al, 2012). Naltrexone antagonism unmasks tonic HPA axis activation, producing a robust cortisol response (Lovallo et al, 2012; Mendelson et al, 1986). We reasoned that, if the diminished stress cortisol response in GA/GG women were a result of high mu-opioid receptor affinity, then naltrexone blockade would disinhibit the system and unmask a large stress-like cortisol response in GA/GG women that would be similar to the same response in AA carriers. Similarly, if men have a large stress cortisol response due to a low tonic opioid regulation, we would see equal, and small, cortisol responses to naltrexone in men with GA/GG and AA genotypes.

\section{MATERIALS AND METHODS}

\section{Subjects}

Subjects were healthy young adults taking part in the Oklahoma Family Health Patterns project, a broad-based study of risk factors for alcoholism (Lovallo et al, 2006). The project currently has 522 participants of whom 276 were genotyped for the OPRM1 A118G polymorphism. Each
Table I Demographic and Biomorphic Characteristics of Male and Female OPRMI Genotype Groups

\begin{tabular}{|c|c|c|c|c|c|}
\hline & \multicolumn{2}{|c|}{ Female } & \multicolumn{2}{|c|}{ Male } & \multirow[b]{2}{*}{$p$-value } \\
\hline & GA/GG & AA & GA/GG & AA & \\
\hline \multicolumn{6}{|l|}{ Stress protocol } \\
\hline$N=25 I$ & 39 & 110 & 30 & 72 & \\
\hline Age, years & $23.3(0.4)$ & $23.3(0.3)$ & $24.0(0.5)$ & $24.0(0.5)$ & 0.76 \\
\hline Education (years) & I $5.6(0.3)$ & I $5.6(0.2)$ & | $5.9(0.3)$ & I $5.8(0.2)$ & 0.79 \\
\hline $\mathrm{SES}^{\mathrm{a}}$ & $45(2.1)$ & $47(1.2)$ & $51(2.3)$ & $49(1.5)$ & 0.33 \\
\hline AIMS Eur (\%) & 95.2 & 95.5 & 96.1 & 95.6 & 0.67 \\
\hline Smoker $(\%, n)$ & 3,1 & 7,8 & 3,1 & 8,6 & 0.97 \\
\hline BMI $\left(\mathrm{kg} / \mathrm{m}^{2}\right)^{\mathrm{a}}$ & $22.5(0.5)$ & $23.0(0.3)$ & $25.3(0.6)$ & $24.4(0.3)$ & 0.11 \\
\hline HC (\%) & 25 & 25 & - & - & \\
\hline \multicolumn{6}{|l|}{ Naltrexone protocol } \\
\hline$N$ & 16 & 48 & 18 & 37 & \\
\hline Age & $23.3(0.7)$ & $23.8(0.3)$ & $23.8(0.5)$ & $24.0(0.4)$ & 0.7551 \\
\hline Education (years) & $15.2(0.5)$ & | $6.1(0.3)$ & I $6.3(0.4)$ & $16.2(0.3)$ & 0.1785 \\
\hline SES & $47.2(3.3)$ & $47.4(1.7)$ & $50.7(3.0)$ & $48.5(1.7)$ & 0.6253 \\
\hline AIMS Eur & 95.45 & 95.00 & 97.20 & 95.20 & 0.4910 \\
\hline Smokers $(\%, n)$ & 0 & $8(4)$ & $6(1$ & $8(3)$ & 0.5761 \\
\hline $\mathrm{BMI}^{\mathrm{a}}$ & $22.1(0.6)$ & $22.6(0.4)$ & $25.0(0.8)$ & $24.5(0.5)$ & 0.3843 \\
\hline $\mathrm{HC}(\%)$ & 18.75 & 41.67 & - & - & \\
\hline
\end{tabular}

Abbreviations: AIMS, Median percentage of European ancestry informative markers; HC, hormonal contraceptive; SES, socioeconomic status using Hollingshead and Redlich's system. Entries show mean \pm SEM or median \%. Significance values refer to $\mathrm{F}$ ratio of the Sex $\times$ Genotype interaction or $X^{2}$ in the case of percentages.

asignificant main effect of Sex, $p<0.05$.

subject signed a consent form approved by the Institutional Review Board of the University of Oklahoma Health Sciences Center and the Veterans Affairs Medical Center, Oklahoma City, OK, USA and received financial compensation. Demographic characteristics are shown in Table 1.

\section{Inclusion and Exclusion Criteria}

Subjects were healthy, 18-30-year-old men and women. Prospective volunteers were excluded if they had: a history of alcohol or drug dependence; substance abuse within the past 2 months; a positive urine screen for abused drugs (iCup, Instant Technologies, Norfolk, VA) or breath-alcohol test on days of testing; or a history of Axis I disorder, other than past depression ( $>60$ days), a body mass index $>30 \mathrm{~kg} / \mathrm{m}^{2}$, used prescription medications other than hormonal contraceptives, or had a serious medical disorder. Women had a negative urine pregnancy test on each day of testing. Smoking and smokeless tobacco use were not exclusionary. Twenty-one subjects (8.3\%) reported using tobacco. Because HapMap data indicate that the G allele is nearly absent in persons of African ancestry, the current sample included only the 251 individuals (149 females) with $<50 \%$ African ancestry based on ancestry informative markers (AIMS). The final sample had a median value of 95\% Caucasian ancestry (Table 1). The remaining 5\% included persons self-described as Native American, Asian, or Other. 


\section{Study Design and Procedure}

Subjects visited the laboratory two times, at the same time on both days, either in at 0900 hours $(N=111)$ or at 1300 hours $(N=140)$. The first laboratory day involved the stress procedure and the second day was a resting control day. This fixed order was chosen to maximize the stress response by reinforcing it with exposure to a novel test environment, and this order similarly reinforced a basal state on the rest day due to greater familiarity with the situation and due to the knowledge that the stress day was past (Lovallo et al, 2010a).

Stress and Rest Day Protocols. The stress protocol consisted of a 30-min prestress baseline, when the subject sat quietly and read general interest magazines, followed by $45 \mathrm{~min}$ of behavioral stress, and $30 \mathrm{~min}$ of recovery. Stress included simulated public speaking (30 min) (Saab et al, 1989 ) followed by mental arithmetic ( $15 \mathrm{~min})$. The rest day protocol lasted for the same duration as on the stress day, during which the subject sat and read general interest magazines or watched nature or history programs. Stress and rest protocols were separated by 1-30 days based on scheduling requirements.

Stressors. The speech task $(30 \mathrm{~min})$ included three successive speeches prepared and delivered with no breaks. At the start of each speech period, the subject was given a card with a topic written on it and told that they had $4 \mathrm{~min}$ to prepare a speech without making notes and 4-min to deliver it from memory. To increase the sense of realism, the speech was observed by a white-coated experimenter holding a clipboard and with a nearby video camera set to the record mode. The subject was told that his or her speech would be shown to the laboratory staff and that they would judge the subject's fluency of delivery and how convincing their speech was. The speech topics included recounting an article on why hair turns gray, presenting a position for or against whether homosexuals should be allowed to marry, and responding to an accusation that the subject was shoplifting. The order of speech topics was randomly assigned for each participant. The 15-min mental arithmetic task consisted of three 5-min periods with no interruption other than brief instructions. At the start of each period, the subject was given a three-digit number (eg, 298) and told to add the digits (19) and to add that total to the original number (317), to recite the new number aloud, and to proceed in that manner for $5 \mathrm{~min}$ until told to stop. The experimenter monitored the answers and noted errors by telling the subject when an answer was wrong and to start back with their previous correct answer.

Naltrexone Challenge Protocol. Cortisol response to naltrexone was measured in 119 subjects who had participated in the stress protocol and who also had been genotyped. The challenge protocol was a randomized, placebo-controlled, double-blind administration of placebo $v s$ oral naltrexone (50 mg, Malinkrodt, St Louis, MO, USA) given in identical appearing capsules prepared by Innovative Pharmacy Solutions (Edmond, OK, USA). The naltrexone protocol was always held after the stress protocol, and naltrexone and placebo days were separated by a minimum of $72 \mathrm{~h}$. The subject entered the General Clinical Research Center at the University of Oklahoma Health Sciences Center at
0800 hours, provided a urine sample to check for the presence of opiates or other drugs, and was served a light breakfast. At 0900 hours, he or she provided a baseline saliva sample and immediately consumed the naltrexone or placebo capsule. Saliva was then collected every $30 \mathrm{~min}$ for the next $180 \mathrm{~min}$. The subject remained seated in a recliner chair through the entire protocol and read general interest magazines or watched videos of nature or history programs. A research nurse monitored subjects during the protocol.

\section{Saliva Collection}

Free cortisol was analyzed from saliva samples. Saliva-free cortisol is unaffected by saliva flow rate, and it is significantly correlated with total cortisol values measured in blood (Aardal and Holm, 1995; Kirschbaum and Hellhammer, 1989; Riad-Fahmy et al, 1983). On all the test days, subjects were instructed to avoid alcohol and caffeine starting at midnight. Blood glucose levels affect cortisol secretion, and in order to standardize postprandial state subjects were told that they would consume a standard meal prior to the start of the day's protocol. Breakfast or lunch was provided in the form of a frozen packaged meal or a fruit cup and an $8-\mathrm{oz}$ serving of yoghurt. Collection times in the home and compliance with preparation instructions were documented with a self-report questionnaire completed after arriving at the laboratory.

Saliva was collected using the Salivette device (Sarstedt, Newton, NC, USA). In the stress protocol, saliva was collected at home, both upon awakening and at bedtime, and also in the laboratory upon arrival (Pre-Baseline) and again at minutes 0 and 15 of the 30 -min baseline period and at minutes 0,30 , and 45 of the stress protocol and at the end of a $30-\mathrm{min}$ poststress recovery period. Samples were collected at the same times on the rest day, and these values were therefore considered to represent a diurnal curve across the waking hours (Lovallo et al, 2010a). During the naltrexone protocol, saliva was collected at baseline and then every $30 \mathrm{~min}$ for the next 180 min (Lovallo et al, 2012).

Cortisol Assay. Salivettes were centrifuged at $4200 \mathrm{RPM}$ for $20 \mathrm{~min}$ and stored at $-20^{\circ} \mathrm{C}$ until shipping to Salimetrics where saliva-free cortisol was quantified using a competitive enzymatic immunoassay (High-Sensitivity Salivary Cortisol Enzyme Immunoassay Kit; State College, PA, USA). The assay has a sensitivity of $<0.083 \mu \mathrm{g} / \mathrm{dl}$ and an interassay coefficient of variation of $<6.42 \%$.

\section{Heart Rate}

Heart rate was recorded from a Dinamap oscillometric blood pressure and heart rate monitor (Critikon, Jacksonville, FL, USA) set to record every 2 min throughout the stress and rest protocols.

\section{Subjective Responses}

Subjective states were recorded at three time points (prestress, poststress, and at the end of recovery on the stress day and comparable times on the rest day) using 10point visual-analog scales containing Distress and Activation subscales (Lundberg, 1980). 


\section{a}



c

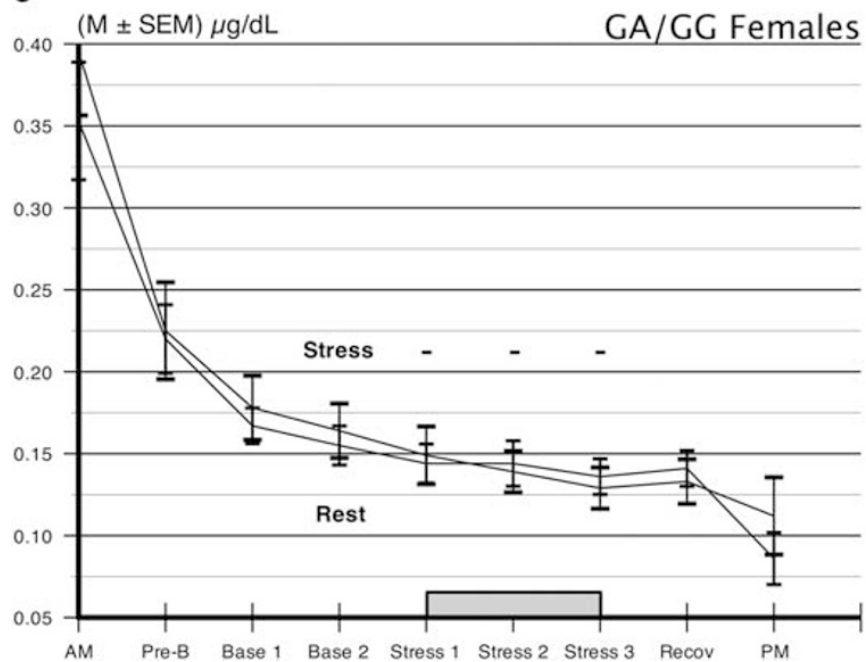

b

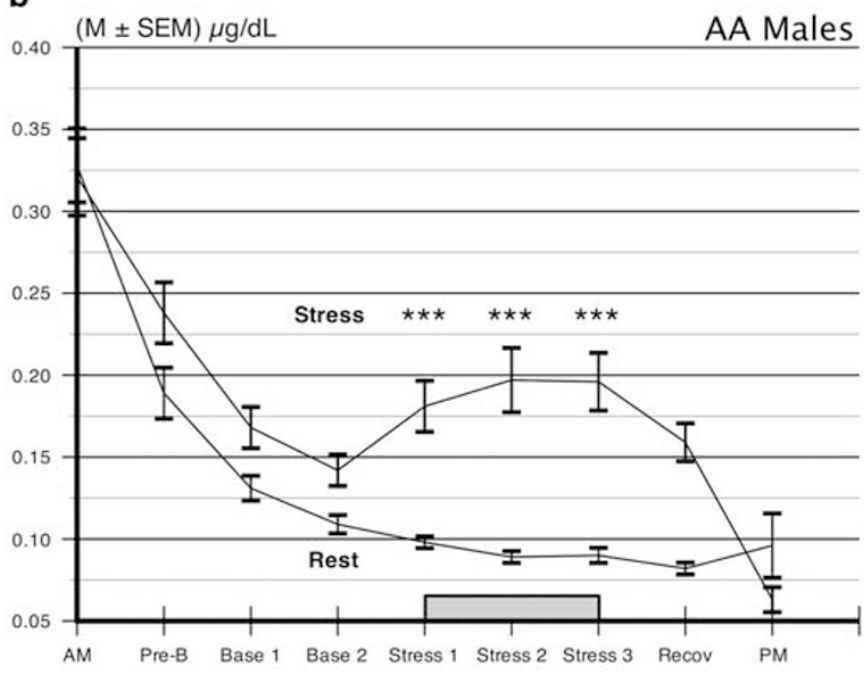

d

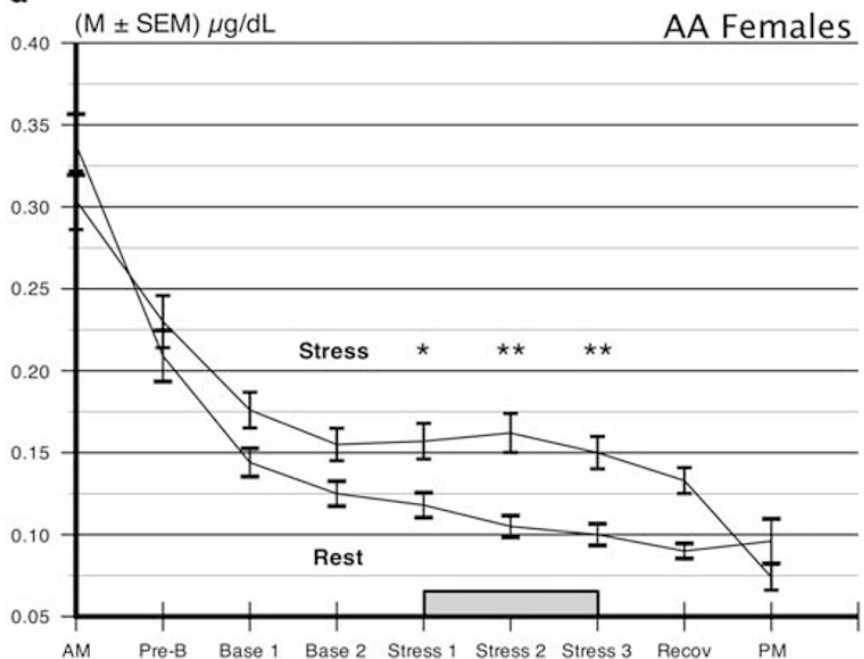

Figure I Cortisol secretion across stress and nonstress days in (a, b) men and (c, d) women with OPRM I AII8G GA/GG vs AA genotypes. Genotype had no effect on cortisol responses to mental stress in men. Female $G$ allele carrier had no stress response at any time point. Women carrying the AA genotype had the expected cortisol response. $-p>0.10,{ }^{*} p<0.002$, $* * 00.000$ I by Student's $t$ test following analysis of variance.

\section{Genotyping}

Subjects provided a saliva sample by passive drool into an Oragene Collection and Preservation Kit (DNA Genotek, Kanata, Ontario, Canada). DNA samples were genotyped using the Illumina OmniExpress array using standard protocols. Samples with call rates $<95 \%$ were excluded, and randomly selected samples showed an average reproducibility of $99.998 \%$. The genotype completion rate was 0.993 (using a cutoff of 0.95 call rate). Genotypes for the OPRM1 SNP rs1799971 were available on the array and were in Hardy-Weinberg equilibrium $(p=0.84)$. Genotype data obtained from 305 subjects using the HumanOmniExpress array for rs1799971 has been compared against data obtained using TaqMan genotyping. The concordance rate was $99 \%$ with three genotyping discrepancies (a single allele in each case) corresponding to an effective error rate of $0.5 \%$, a level of error typically observed with TaqMan data, providing high confidence that data obtained from the array are accurate and correspond to rs1799971.
Assessment of Population Stratification using AIMS. A panel of 2491 SNPs from the Illumina OmniExpress array was selected as AIMS based on the following criteria: (a) large differences in the reference allele frequency of pairwise SNPs from the HapMap Project between African, Chinese, and European populations; (b) mapping on different chromosomes or in different regions of the same chromosome; and (c) shared by both Illumina Human Hap550v3 and HumanOmniExpress-12v1 array. Individual ethnic factor scores corresponding to geographical regions: Africa, Europe, Middle East, Central Asia, Far East Asia, Oceania, and America was estimated using the STRUCTURE v2.3 software and using a known set of 1051 subjects representing 51 worldwide populations (CEPH population) as a reference (http://www.cephb.fr/HGDP-CEPH-Panel). The Caucasian ancestry of this sample is as follows: mean (SD), median: 0.94 (0.09), 0.95. The $\mathrm{G}$ allele frequency in this sample is 0.15 . This is virtually the same as in the HapMap Caucasians (0.155). 
a

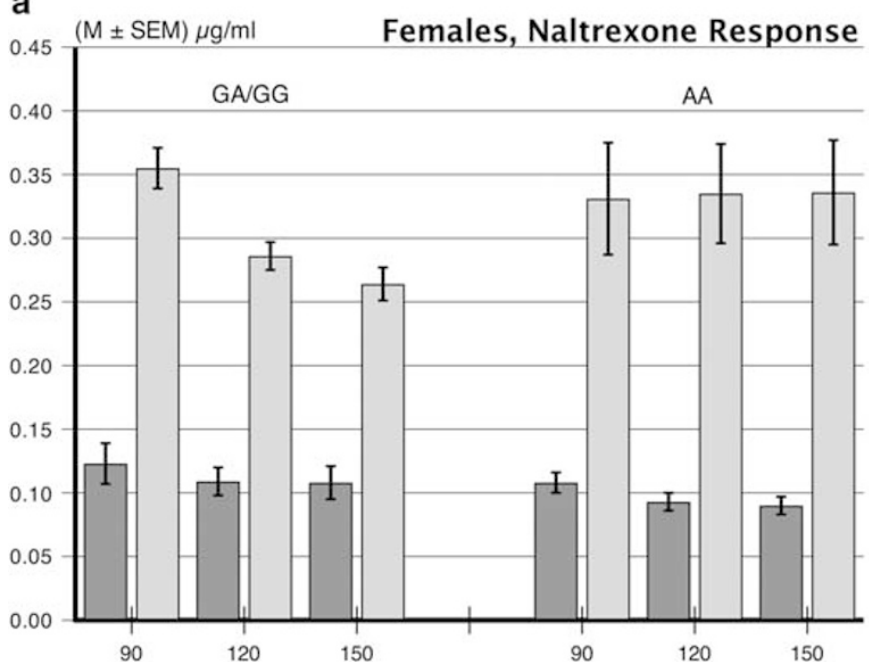

b

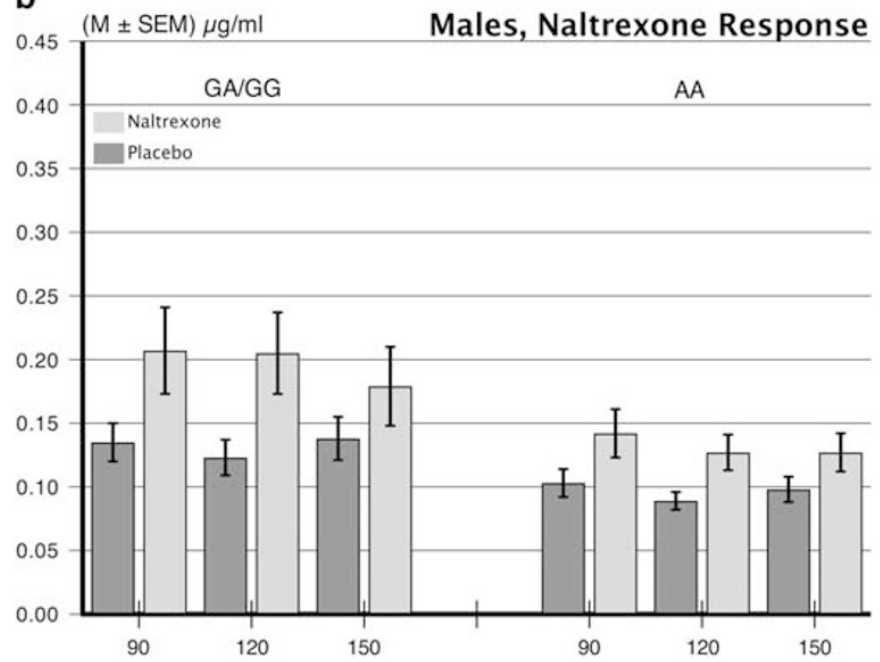

Figure 2 Cortisol responses to $50 \mathrm{mg}$ naltrexone in men and women with OPRM / AI I 8G GA/GG vs AA genotypes. (a) Females in both genotype groups had a robust cortisol response to naltrexone, consistent with unmasking a mu-opioid receptor-associated inhibition of the hypothalamic-pituitaryadrenocortical (HPA) axis. (b) Males have minimal cortisol responses to naltrexone, indicating a lack of tonic opioid inhibition of the HPA.

\section{Data Analysis}

Cortisol responses to stress were viewed as the difference in cortisol values during the stress protocol on the stress day compared with the cortisol values on the resting control day as the latter values provide a highly reliable reference point for changes seen during stress, as discussed previously (Lovallo et al, 2010a). Cortisol and heart rate data were analyzed by repeated-measures analyses of variance, including Sex $\times$ Genotype $(\mathrm{AA}, \mathrm{GA} / \mathrm{GG}) \times$ Day (rest, stress; equivalent to the stress effect) $\times$ Time Period (Stress 1, 2, and 3 in Figure 1). In the case of predicted genotype effects, exploratory analyses were done separately for the males and females, including Genotype $\times$ Day $\times$ Time Period. Follow-up analyses were done on individual time periods using Student's $t$-test, with a step-down Bonferroni correction for multiple comparisons. In the females, we tested for the effects of hormonal contraceptive status in a model including Hormonal Contraceptive Status $(Y e s, \mathrm{No}) \times$ Genotype $\times$ Day $\times$ Time Period. Additional tests of possible confounders included controls for smoking status and time of day of testing. Tests were considered statistically significant if $p<0.05$. Analyses were conducted using SPSS for Windows (release 18.0, SPSS, Chicago, IL, USA).

\section{RESULTS}

Table 1 indicates that there were no significant differences on demographic and biomorphic variables between men and women as a function of the OPRM1 A118G genotype.

\section{Cortisol Responses to Stress}

Figure 1 shows saliva cortisol values on the rest and stress days for the OPRM1 A118G genotypes in men and women. We saw the expected elevation of cortisol on the stress $v s$ rest day for all subjects $(\mathrm{F}=187, p<0.00001)$. Women had significant stress $v s$ rest day cortisol responses $(\mathrm{F}=22.98$, $p<0.0001$ ), although a significant Sex $\times$ Day interaction indicated that their responses were smaller than those in men $(\mathrm{F}=10.24, p=0.002)$. Relative to the present question, we observed a genotype difference in stress reactivity in the full sample as indicated by a significant Genotype $\times$ Day interaction $(\mathrm{F}=9.08, p=0.003)$ consistent with a greater cortisol response in the AA OPRM1 genotype group relative to the GA/GG groups. Finally, this stress effect on the genotype groups was different in men and women, as shown by a significant Sex $\times$ Genotype $\times$ Day interaction term $(\mathrm{F}=4.42, p=0.037)$.

This interaction is qualified by separate results for men and women. In Figure 1, panels a and b show that, in men, both genotypes had similarly large cortisol responses to the stressors (nonsignificant Genotype $\times$ Day interaction term, $\mathrm{F}<1.0$ ). In contrast, panels $\mathrm{c}$ and $\mathrm{d}$ indicate that women responded differently as a function of OPRM1 A118G genotype, as revealed in a significant Day $\times$ Genotype interaction $(\mathrm{F}=18.40, p<0.0001)$. This interaction term was unchanged when we included resting day values in the model as covariates $(\mathrm{F}=18.34, p<0.0001)$. In deconstructing this interaction effect, we conducted $t$-tests at each time point corresponding to the stress period in the laboratory. As seen in panel c, GA/GG females had virtually no response to the stress procedure at any time point (all $p s>0.60$ ) while panel $\mathrm{d}$ shows the AA females had a significant cortisol response at each time during the stress protocol $(t s \geqslant 2.46, p s<0.002)$.

\section{Cortisol Responses to Naltrexone Challenge}

To explore the opioid nature of OPRM1 A118G genotype difference in cortisol reactivity, we tested a subgroup of 119 subjects (70 women) for cortisol response to naltrexone challenge as shown in Table 1, lower panel, and Figure 2. We first ran an overall analysis on cortisol in the naltrexone protocol including Day (Drug = naltrexone, placebo), Period (all sample time points), Sex, and OPRM1 genotype. The Sex $\times$ Day interaction was significant $(\mathrm{F}=58.54, p<0.0001)$ consistent with women reacting more strongly to naltrexone than men. We next compared the effect of naltrexone on 
cortisol secretion separately for men and women (Lovallo et al, 2012) in a model including Genotype $\times$ Day (naltrexone, placebo) $\times$ Time Period $(90,120$, and $150 \mathrm{~min}$ postnaltrexone) and the interactions. Women in both the GA/GG and AA genotype groups had significant, and equally large, cortisol responses from 90 to $150 \mathrm{~min}$ following naltrexone relative to the placebo day (Day effect, $\mathrm{F}=123, p<0.0001$ ), along with a nonsignificant Day $\times$ Genotype interaction term $(\mathrm{F}=1.67, p=0.200)$, and no difference in pattern of response over time (nonsignificant Day $\times O P R M 1 \times$ Period term, $\mathrm{F}<1.0$ ). Men also showed a significant cortisol response to naltrexone $(\mathrm{F}=43.71, p<0.0001)$ and similar responses in both the genotype groups (nonsignificant Day $\times$ Genotype interaction, $\mathrm{F}=3.67, p=0.061)$. Sex differences in cortisol response to naltrexone were not related to differences in body weight or body mass index within this sample (Lovallo et al, 2012).

\section{Potential Confounders}

We examined potential confounders that might have affected the original Sex $\times$ OPRM1 Genotype $\times$ Stress Day interaction $(\mathrm{F}=4.42, p=0.037)$ in the full sample or the OPRM1 Genotype $\times$ Stress Day interaction among women $(\mathrm{F}=18.40, p<0.0001)$. Inclusion of time of day of testing as a covariate had no effect on either the Sex $\times$ Genotype $\times$ Day interaction from the full ANOVA $(F=4.42, p=0.037)$ or on the Genotype $\times$ Day interaction on the ANOVA among women $(\mathrm{F}=18.34, p<0.0001)$. Similarly, inclusion of smoking status as a covariate in the full model left the Sex $\times$ OPRM1 Genotype $\times$ Stress Day interaction unchanged $(\mathrm{F}=4.42, p=0.037)$.

Hormonal contraceptive use and menstrual cycle phase are both known to affect cortisol responsivity to stress. In the present data, women using hormonal contraceptives had smaller stress cortisol responses than those using no contraceptives $(\mathrm{F}=9.25, p=0.003)$; however, no interactions were found between hormonal contraceptive status and the other main effects or interactions. Similarly, when we included follicular vs luteal menstrual cycle phase as a covariate in the ANOVA model for a subset of 97 (65\%) of the women for whom we had information, the OPRM $1 \times$ Day interaction remained significant, $\mathrm{F}=16.03, p<0.0001$.

See Online Supplementary Information for additional details.

\section{Heart Rate Responses}

We examined heart rates separately in men and women using a model including Genotype $\times$ Day $\times$ Time Period (Baseline, Stress, Recovery). The 3-way interaction of Genotype $\times$ Day $\times$ Time Period was nonsignificant for men $(\mathrm{F}=1.36, p=0.258)$ and for women $(\mathrm{F}=1.18, p=0.309)$ indicating no differential effect of stress on this autonomically regulated response to stress in the GA/GG genotype in men or women. See Supplementary Figure S2.

\section{Subjective Responses}

Cortisol is elevated during periods of negative affect (Buchanan et al, 1999). Accordingly, examination of selfreported experience of Activation and Distress can be useful in determining whether the present results are driven by psychological response differences for men and women in the OPRM1 genotype groups. We observed the expected stress-day increases in arousal (Activation scale) and negative affect (Distress scale) (effects of Day, Fs $\geqslant 48$, $p s<0.0001)$ with greater levels reported by women on both scales (effects of Sex, Fs $\geqslant 6.11$, ps $<0.014$ ). Subjective reports did not vary as a function of any OPRM1 genotype main effect $(\mathrm{F} \leqslant 1.28, \quad p s>0.259)$ or interaction $(\mathrm{Fs} \geqslant 2.37$, $p s>0.12$ ). See Online Supplementary Information.

\section{DISCUSSION}

Cortisol responses to mental stress are larger in men than in women (Lovallo et al, 2010a), whereas cortisol responses to mu-opioid receptor blockade by naltrexone are large in women and small in men (Lovallo et al, 2012). These results imply that women have a high degree of endogenous HPA axis regulation and that this restraint is unmasked by the cortisol response to naltrexone antagonism. Given this potential sex difference in opioid regulation of the HPA axis, in the present analysis we examined whether the muopioid receptor gene polymorphism OPRM1 A118G would have differential effects on HPA activity in men compared with women. We show here that women carrying the OPRM1 G allele had virtually no response to mental stress while female AA-allele carriers had a normal response, a novel finding in the present study. In probing the opioid nature of this difference using naltrexone antagonism, we observed large and equal cortisol responses from women carrying both GA/GG and AA genotypes. These joint findings under stress and following opioid antagonism are consistent with an endogenous opioid restraint on the HPA axis that affects stress reactivity via the mu-opioid receptor. In contrast, men have large cortisol responses to stress and very small responses to naltrexone antagonism (Lovallo et al, 2012), consistent with a reduced opioid regulation of the HPA axis that therefore appears insensitive to OPRM1 A118G polymorphism. The greater endogenous opioid restraint over the HPA axis in women with GA/GG OPRM1 genotypes is in keeping with a report of higher mu-opioid receptor-binding affinity in $G$ allele carriers (Bond et al, 1998) and also consistent with related findings of Wand and colleagues (Chong et al, 2006), although not all studies support higher binding affinity in $\mathrm{G}$ allele receptors.

The above findings are subject to several limitations and the impact of potential confounders. Most importantly, the laboratory stressor challenge used here is a combination of mental arithmetic and simulated public speaking (al'Absi et al, 1997). Caution should be exercised in generalizing these findings to experience outside the laboratory. Similarly, the results are confined to a single dose of naltrexone. In structuring the study, we chose to have all subjects exposed to the stressor on day 1 and to rest on day 2. This fixed order was chosen with the explicit purpose of maximizing the stress reactivity scores. A counterbalanced order of presentation might reduce the magnitude of reactivity overall but would be less likely to alter the relationships between the $O P R M 1$ groups as reported here. We also examined potential confounders. The GA/GG allele women exhibited nonsignificantly higher basal cortisol values during the stress 
protocol, possibly attenuating the stress response due to a ceiling effect or negative feedback dampening of HPA reactivity. An elevated baseline is not a persistent characteristic of the GA/GG allele genotype; the female genotype groups exhibited no baseline differences during the placebo condition in the naltrexone protocol (Figure 2), as also found by others (Chong et al, 2008). Another group reported elevated cortisol secretion in AA women (Bart et al, 2006). The levels of cortisol output achieved by the women during the stress protocol (Figure 1) do not exhaust the response capacity of the HPA as indicated by the higher levels achieved following naltrexone administration (Figure 2). Additional confounder analyses indicated that the results were not accounted for by use of hormonal contraceptives, phase of menstrual cycle, smoking status, or morning vs afternoon test sessions.

The effect of the OPRM1 A118G genotype was apparently confined to cortisol reactivity to stress. Heart rate and subjective report data showed no evidence of differential stress reactivity in women or men with the GA/GG genotypes relative to the AA. This suggests that the diminished HPA axis response to stress in the female G allele carriers was not secondary to a generalized HPA response deficit, which should have affected heart rate, or a difference in perception of the stressors that would affect self-reports, which are otherwise associated with cortisol secretion to stress and negative affect (Buchanan et al, 1999; Smyth et al, 1998). One other study also found that OPRM1 A118G polymorphism did not influence alcohol craving or feelings of tension or negative moods in response to recall of personally experienced stressful events (Ray, 2011).

The differential effect of the OPRM1 genotype on cortisol responses to stress in women raises the question of the nature of this sex effect. Women show variations in cortisol stress reactivity as a function of the menstrual cycle (Kudielka et al, 2009) and use of hormonal contraceptives (Kirschbaum et al, 1999; Roche et al, 2013). Similarly, cortisol response to naltrexone is larger during the luteal phase of the menstrual cycle relative to the follicular phase (Roche and King, 2015). We have reported that women as a group have large cortisol responses to $50 \mathrm{mg}$ naltrexone relative to men (Lovallo et al, 2012), suggesting a greater degree of mu-opioid receptor restraint over the endogenous activity of the HPA in women that attenuates stress reactivity and is unmasked by opioid antagonism. Because women have a generally greater degree of opioid system regulation of the HPA axis, they also appear to manifest variation in HPA axis function in relation to the OPRM1 A118G polymorphism that is absent in men. The present results are consistent with global effects of female sex steroids on the HPA axis but that these hormonal effects do not account for differential HPA effects of the OPRM1 A118G polymorphism. Nonetheless, specific tests of gonadal steroid effects on cortisol reactivity in women differing in OPRM1 genotypes remains an avenue for further study.

The present findings of the impact of the OPRM1 A118G allele in women may bear clinical significance for behavior and perhaps for risk for alcoholism. Cortisol constitutes an important source of regulatory feedback to the CNS during basal states and following acute stress (De Kloet and Reul, 1987), evidenced by the presence of glucocorticoid receptors above the hypothalamus in the hippocampus, amygdala, medial prefrontal cortex, anterior cingulate gyrus, and ventral striatum (McEwen et al, 1968; Sanchez et al, 2000). The behavioral relevance of cortisol feedback is illustrated by studies using hydrocortisone to mimic the glucocorticoid feedback limb of a normal stress response. (a) Functional magnetic resonance scans following $10 \mathrm{mg}$ intravenous hydrocortisone injection showed rapid uptake $(15 \mathrm{~min})$ in the hippocampus and amygdala, resulting in diminished activation of those structures (Lovallo et al, 2010b). (b) Hydrocortisone $(20 \mathrm{mg}$ ) acutely suppresses the startle reflex (Buchanan et al, 2001a), thereby modulating behavioral responses to sudden, unexpected stimuli during stress episodes. (c) In young adults, hydrocortisone enhanced hippocampal responses to infant cries, an effect that was modulated by previous experience of parental neglect (Bos et al, 2014). (d) A longer-term effect of stress-level hydrocortisone administration in human volunteers was seen in enhanced declarative memory for emotional material 1 week after exposure (Buchanan and Lovallo, 2001b). (e) On the other hand, chronically high cortisol levels can also impair declarative memory due to suppression of hippocampal cell formation in the dentate gyrus (Sapolsky et al, 1985). At a clinical level, persons with chronically diminished glucocorticoid secretion show antisocial and aggressive tendencies (Kim and Haller, 2007). In healthy persons, cortisol secretion varies with fluctuations in negative affect, increasing along with negative affect during mental stress (Lovallo et al, 1990), and decreasing when negative affect is minimized while viewing a positive and uplifting film (Buchanan et al, 1999). Diminished cortisol responses to stress predict earlier relapse in persons attempting to quit smoking and in patients undergoing treatment for addiction (al'Absi, 2006; Sinha et al, 2011). These collective findings suggest the value of further study of possible consequences of stress in women carrying the OPRM1 GA/GG alleles vs AA alleles.

The impact of cortisol feedback on behavior raises three questions related to the present findings: (a) Do women carrying the GA/GG OPRM1 genotypes show different approach and avoidance behaviors in relation to risks and rewards? (b) Are these same women more sensitive to the behavioral consequences of adverse early life experience? (c) Does a diminished cortisol response to stress increase risk for addiction as suggested by others (Lu and Richardson, 2014)?. Although the present sample is large for a laboratory-based study ( $N=251$, with 149 females), it includes only 39 female $\mathrm{G}$ allele carriers. This relatively small sample size limits our current ability to explore such behavioral variation in depth.

\section{CONCLUSION}

The OPRM1 A118G polymorphism produces significant variation in cortisol reactions to psychological stress among women. Women carrying the $G$ allele had no cortisol response to combined mental arithmetic and simulated public speaking stressors in contrast to AA carriers. No effect of OPRM1 A118G genotype was seen in men. The blunted cortisol response in female $G$ allele carriers appears to be consistent with a high-affinity of the mu-opioid receptor for endogenous opioids. Unmasking this effect by naltrexone led to equally large cortisol responses in GA/GG and AA women. 
The absence of a stress cortisol response in women carrying the $G$ allele suggests the need for studies of affective, cognitive, and behavioral characteristics in this subset of women and in relation to their life experience. Such investigations may prove useful in disentangling environmental and genetic determinants of stress reactivity and the influence of differences in stress reactivity on health outcomes.

\section{FUNDING AND DISCLOSURE}

This work was supported by Department of Veterans Affairs Medical Research Service; NIH Grants NIRR M01 RR014467, NIAAA R01AA019691 and R01 AA012207; and the NIAAA Intramural Research Program. The content is solely the view of the authors and does not necessarily represent the official view of the National Institutes of Health or the Department of Veterans Affairs. Dr Vincent receives income from the University of Oklahoma Department of Psychology, the University of Oklahoma Health Sciences Center Department of Psychiatry and Behavioral Sciences, and the Cognitive Science Research Center at the University of Oklahoma. None of these sources involves producing a product that is used or featured as a result of this research. The authors declare no conflict of interest.

\section{REFERENCES}

Aardal E, Holm A.C. (1995). Cortisol in saliva-reference ranges and relation to cortisol in serum. Eur J Clin Chem Clin Biochem 33: $927-932$.

al'Absi M (2006). Hypothalamic-pituitary-adrenocortical responses to psychological stress and risk for smoking relapse. Int $J$ Psychophysiol 59: 218-227.

al'Absi M, Bongard S, Buchanan T, Pincomb GA, Licinio J, Lovallo WR (1997). Cardiovascular and neuroendocrine adjustment to public speaking and mental arithmetic stressors. Psychophysiology 34: 266-275.

Bart G, LaForge KS, Borg L, Lilly C, Ho A, Kreek MJ (2006). Altered levels of basal cortisol in healthy subjects with a $118 \mathrm{G}$ allele in exon 1 of the Mu opioid receptor gene. Neuropsychopharmacology 31: 2313-2317.

Beyer A, Koch T, Schroder H, Schulz S, Hollt V (2004). Effect of the A118G polymorphism on binding affinity, potency and agonistmediated endocytosis, desensitization, and resensitization of the human mu-opioid receptor. J Neurochem 89: 553-560.

Bilkei-Gorzo A, Racz I, Michel K, Mauer D, Zimmer A, Klingmuller D et al (2008). Control of hormonal stress reactivity by the endogenous opioid system. Psychoneuroendocrinology 33: 425-436.

Bond C, LaForge KS, Tian M, Melia D, Zhang S, Borg L et al (1998). Single-nucleotide polymorphism in the human $\mathrm{mu}$ opioid receptor gene alters beta-endorphin binding and activity: possible implications for opiate addiction. Proc Natl Acad Sci USA 95: 9608-9613.

Bos PA, Montoya ER, Terburg D, van Honk J (2014). Cortisol administration increases hippocampal activation to infant crying in males depending on childhood neglect. Hum Brain Mapp.

Buchanan TW, al'Absi M, Lovallo WR (1999). Cortisol fluctuates with increases and decreases in negative affect. Psychoneuroendocrinology 24: 227-241.

Buchanan TW, Brechtel A, Sollers JJ, Lovallo WR (2001a). Exogenous cortisol exerts effects on the startle reflex independent of emotional modulation. Pharmacol Biochem Behav 68: 203-210.
Buchanan TW, Lovallo WR (2001b). Enhanced memory for emotional material following stress-level cortisol treatment in humans. Psychoneuroendocrinology 26: 307-317.

Chong RY, Oswald L, Yang X, Uhart M, Lin PI, Wand GS (2006). The mu-opioid receptor polymorphism A118G predicts cortisol responses to naloxone and stress. Neuropsychopharmacology 31: 204-211.

Chong RY, Uhart M, McCaul ME, Johnson E, Wand GS (2008). Whites have a more robust hypothalamic-pituitary-adrenal axis response to a psychological stressor than blacks. Psychoneuroendocrinology 33: 246-254.

Dallman MF, Akana SF, Jacobson L, Levin N, Cascio CS, Shinsako J (1987). Characterization of corticosterone feedback regulation of ACTH secretion. Ann NY Acad Sci 512: 402-414.

De Kloet ER, Reul JM (1987). Feedback action and tonic influence of corticosteroids on brain function: a concept arising from the heterogeneity of brain receptor systems. Psychoneuroendocrinology 12: 83-105.

Drolet G, Dumont EC, Gosselin I, Kinkead R, Laforest S, Trottier JF (2001). Role of endogenous opioid system in the regulation of the stress response. Prog Neuropsychopharmacol Biol Psychiatry 25: 729-741.

Job MO, Tang A, Hall FS, Sora I, Uhl GR, Bergeson SE et al (2007). $\mathrm{Mu}(\mathrm{mu})$ opioid receptor regulation of ethanol-induced dopamine response in the ventral striatum: evidence of genotype specific sexual dimorphic epistasis. Biol Psychiatry 62: 627-634.

Kim JJ, Haller J (2007). Glucocorticoid hyper- and hypofunction: stress effects on cognition and aggression. Ann NY Acad Sci 1113: 291-303.

Kirschbaum C, Hellhammer DH (1989). Salivary cortisol in psychobiological research: an overview. Neuropsychobiology 22: 150-169.

Kirschbaum C, Kudielka BM, Gaab J, Schommer NC, Hellhammer DH (1999). Impact of gender, menstrual cycle phase, and oral contraceptives on the activity of the hypothalamus-pituitary-adrenal axis. Psychosom Med 61: 154-162.

Kreek MJ (2001). Drug addictions: molecular and cellular endpoints. Ann NY Acad Sci 937: 1749-6632.

Kroslak T, Laforge KS, Gianotti RJ, Ho A, Nielsen DA, Kreek MJ (2007). The single nucleotide polymorphism A118G alters functional properties of the human mu opioid receptor. J Neurochem 103: 77-87.

Kudielka BM, Hellhammer DH, Wust S (2009). Why do we respond so differently? Reviewing determinants of human salivary cortisol responses to challenge. Psychoneuroendocrinology 34: 2-18.

Kudielka BM, Hellhammer J, Hellhammer DH, Wolf OT, Pirke KM, Varadi E et al (1998). Sex differences in endocrine and psychological responses to psychosocial stress in healthy elderly subjects and the impact of a 2-week dehydroepiandrosterone treatment. J Clin Endocrinol Metab 83: 1756-1761.

Lovallo WR, Farag NH, Vincent AS (2010a). Use of a resting control day in measuring the cortisol response to mental stress: diurnal patterns, time of day, and gender effects. Psychoneuroendocrinology 35: 1253-1258.

Lovallo WR, King AC, Farag NH, Sorocco KH, Cohoon AJ, Vincent AS (2012). Naltrexone effects on cortisol secretion in women and men in relation to a family history of alcoholism: studies from the Oklahoma Family Health Patterns Project. Psychoneuroendocrinology 37: 1922-1928.

Lovallo WR, Pincomb GA, Brackett DJ, Wilson MF (1990). Heart rate reactivity as a predictor of neuroendocrine responses to aversive and appetitive challenges. Psychosom Med 52: 17-26.

Lovallo WR, Robinson JL, Glahn DC, Fox PT (2010b). Acute effects of hydrocortisone on the human brain: an fMRI study. Psychoneuroendocrinology 35: 15-20.

Lovallo WR, Yechiam E, Sorocco KH, Vincent AS, Collins FL (2006). Working memory and decision-making biases in young adults with a family history of alcoholism: studies from the 
Oklahoma Family Health Patterns Project. Alcohol Clin Exp Res 30: 763-773.

Lu YL, Richardson HN (2014). Alcohol, stress hormones, and the prefrontal cortex: a proposed pathway to the dark side of addiction. Neuroscience 277: 139-151.

Lundberg U (1980). Catecholamine and cortisol excretion under psychologically different laboratory conditions. In: Usdin E, Kvetnansky R, Kopin IJ (eds). Catecholamines and Stress: Recent Advances. Elsevier North Holland: New York, NY, USA pp 455-460.

McEwen BS (1998). Protective and damaging effects of stress mediators. $N$ Engl J Med 338: 171-179.

McEwen BS, Weiss JM, Schwartz LS (1968). Selective retention of corticosterone by limbic structures in rat brain. Nature 220: 911-912.

Mendelson JH, Mello NK, Cristofaro P, Skupny A, Ellingboe J (1986). Use of naltrexone as a provocative test for hypothalamicpituitary hormone function. Pharmacol Biochem Behav 24: 309-313.

Nakao K, Nakai Y, Oki S, Horii K, Imura H (1978). Presence of immunoreactive beta-endorphin in normal human plasma: a concomitant release of beta-endorphin with adrenocorticotropin after metyrapone administration. J Clin Invest 62: 1395-1398.

Ray LA (2011). Stress-induced and cue-induced craving for alcohol in heavy drinkers: preliminary evidence of genetic moderation by the OPRM1 and CRH-BP genes. Alcohol Clin Exp Res 35: 166-174.

Riad-Fahmy D, Read GF, Walker RF (1983). Salivary steroid assays for assessing variation in endocrine activity. J Steroid Biochem 19: 265-272.

Roche DJ, King AC (2015). Sex differences in acute hormonal and subjective response to naltrexone: The impact of menstrual cycle phase. Psychoneuroendocrinology 52: 59-71.
Roche DJ, King AC, Cohoon AJ, Lovallo WR (2013). Hormonal contraceptive use diminishes salivary cortisol response to psychosocial stress and naltrexone in healthy women. Pharmacol Biochem Behav 109: 84-90.

Saab PG, Matthews KA, Stoney CM, McDonald RH (1989). Premenopausal and postmenopausal women differ in their cardiovascular and neuroendocrine responses to behavioral stressors. Psychophysiology 26: 270-280.

Sanchez MM, Young LJ, Plotsky PM, Insel TR (2000). Distribution of corticosteroid receptors in the rhesus brain: relative absence of glucocorticoid receptors in the hippocampal formation. J Neurosci 20: 4657-4668.

Sapolsky RM, Krey LC, McEwen BS (1985). Prolonged glucocorticoid exposure reduces hippocampal neuron number: implications for aging. J Neurosci 5: 1222-1227.

Schwandt ML, Lindell SG, Higley JD, Suomi SJ, Heilig M, Barr CS (2011). OPRM1 gene variation influences hypothalamic-pituitaryadrenal axis function in response to a variety of stressors in rhesus macaques. Psychoneuroendocrinology 36: 1303-1311.

Sinha R, Fox HC, Hong KI, Hansen J, Tuit K, Kreek MJ (2011). Effects of adrenal sensitivity, stress- and cue-induced craving, and anxiety on subsequent alcohol relapse and treatment outcomes. Arch Gen Psychiatry 68: 942-952.

Smyth J, Ockenfels MC, Porter L, Kirschbaum C, Hellhammer DH, Stone AA (1998). Stressors and mood measured on a momentary basis are associated with salivary cortisol secretion. Psychoneuroendocrinology 23: 353-370.

Wand GS, McCaul M, Yang X, Reynolds J, Gotjen D, Lee S et al (2002). The mu-opioid receptor gene polymorphism (A118G) alters HPA axis activation induced by opioid receptor blockade. Neuropsychopharmacology 26: 106-114.

Zhang Y, Wang D, Johnson AD, Papp AC, Sadee W (2005). Allelic expression imbalance of human mu opioid receptor (OPRM1) caused by variant A118G. J Biol Chem 280: 32618-32624.

Supplementary Information accompanies the paper on the Neuropsychopharmacology website (http://www.nature.com/npp) 